\title{
Ocupações urbanas em Belo Horizonte e a (re)construção espacial da cidade: um estudo de caso da ocupação Camilo Torres
}

Informal urban settlements in Belo Horizonte (Brazil) and the spatial (re) construction of the city: A case study on Camilo Torres settlement

http://dx.doi.org/10.5007/2178-4582.2015v49n2p205

\author{
Maria Tereza Fonseca Dias, Juliano dos Santos Calixto, \\ Larissa Pirchiner de Oliveira Vieira, Carolina Spyer Vieira Assad \\ Amanda Reis da Silva, Ananda Martins Carvalho \\ Fúlvio Alvarenga Sampaio, Ingrid de Paula, Letícia Leite \\ Lucas Nasser Marques de Souza e Marcos Bernardes Rosa \\ Universidade Federal de Minas Gerais, Belo Horizonte/MG, Brasil
}

\begin{abstract}
O presente artigo apresenta resultados parciais da pesquisa "Pelo direito à moradia adequada: mapeamento das ocupações urbanas de Belo Horizonte e Região Metropolitana", em desenvolvimento no âmbito do Programa Cidade e Alteridade: convivência multicultural e justiça urbana, em parceria com o Programa Pólos de Cidadania da Faculdade de Direito da Universidade Federal de Minas Gerais. Este trabalho objetiva apresentar em que medida e de que forma as ocupações urbanas da Região Metropolitana de Belo Horizonte contribuem para a reconstrução espacial da cidade e propiciam a emergência da cidadania e a redução de desigualdades. Diante de um modelo de cidade pautado pela mercantilização e privatização dos espaços, as ocupações urbanas surgem como instrumento de acesso à moradia adequada e de justiça urbana. Considerando essas questões será apresentada a análise da cartografia social desenvolvida na ocupação Camilo Torres, localizada em Belo Horizonte-MG.
\end{abstract}

Palavras-chave: Ocupação urbana - Direito à Cidade - Direito à Moradia Adequada - Cartografia Social - Belo Horizonte
The present work is part of the main research named "For the right to adequate housing: mapping informal urban settlements in Belo Horizonte City and its Metropolitan Area (Brazil)" developed on the scope of the "City and Otherness Program" in partnership with the "Citizenship Pole Program" - both carried out in the Law School at Federal University of Minas Gerais. This paper aims to present to what extent and how the urban occupation of the Metropolitan Area of Belo Horizonte contribute to the spatial reconstruction of the city and foster the emergence of citizenship and the reduction of inequalities. In the face of a city model based upon commercialization and privatization of space, urban occupations emerge as an instrument of access to adequate housing and urban justice. Considering these issues, it will be presented the analysis of social cartography developed in the occupation Camilo Torres, located in Belo Horizonte-MG.

Keywords: Urban occupation - Right to the City Right to Adequate Housing - Social Cartography - Belo Horizonte Metropolitan Area

\section{Introdução}

Este trabalho é fruto das atividades desenvolvidas pela pesquisa "Pelo direito à moradia adequada: mapeamento das ocupações urbanas de Belo Ho- 
rizonte e Região Metropolitana", que objetiva compreender os processos de constituição e consolidação dos seguintes espaços urbanos da região: Camilo Torres (2008); Dandara (2009); Irmã Dorothy (2010); Eliana Silva (2012); Zilah Spósito (2012); e Emanuel Guarani Kaiowá (2013). A pesquisa visa compreender em que medida e de que forma estas ocupações contribuem para a reconstrução espacial da cidade e propiciam a emergência da cidadania e a redução de desigualdades, a partir da luta pelo acesso à moradia adequada. Neste contexto, o estudo toma como pressuposto, a partir dos estudos de David Harvey (2013), o fato de que ocupação da terra urbana que não cumpre a função social da propriedade constitui importante forma de luta a favor da democratização dos usos da cidade e de questionamento dos poderes que conferem à propriedade caráter eminentemente privado.

Para o delineamento da pesquisa, as ocupações urbanas foram definidas preliminarmente como identidades territorializadas que exercem posse planejada, pacífica e informal em espaços urbanos não utilizados, subutilizados ou não edificados, e se mantêm em mobilização continuada pelo acesso à terra urbana e pelo exercício dos direitos à moradia e à cidade. No caso das seis áreas em estudo, cabe mencionar a organização prolongada das famílias, em conjunto com a atuação de movimentos sociais e organizações populares, para a edificação de casas, ruas e equipamentos de uso comum, bem como para sua consolidação e permanência nas áreas ocupadas.

Tais ocupações, situadas em Belo Horizonte e sua Região Metropolitana, estão inseridas num contexto urbano marcado, histórica e politicamente, pela ausência ou insuficiência de programas habitacionais, pela segregação socioespacial e pelo acirramento espaço-temporal das desigualdades de classe, conforme já descrito, entre outros, por Andrade (2003) e Mendonça e Costa (2004), ao resgatarem o histórico de construção e consolidação do território da cidade de Belo Horizonte e Região Metropolitana.

Belo Horizonte vive hoje um modelo de cidade altamente mercantilizado, em função das dinâmicas do setor imobiliário e até mesmo das ações do poder público, que não implementa os instrumentos de sustentabilidade das cidades descritos no Estatuto da Cidade (Lei n ${ }^{0}$ 10.257/2001). Produz-se, então, o que Vainer (2011) conceituou como cidade-mercadoria, caracterizada por espaços construídos de acordo com a sua funcionalidade imediata, de forma padronizada e em descumprimento a qualquer função coletiva, social ou comum. Quando estudadas as políticas públicas para o provimento de habitação à população e a participação dos movimentos sociais na construção destas políticas, observa-se que, em Belo Horizonte, a discussão da habitação está descolada do direito à cidade (DIAS; COSTA, 2015) 
Ferrari et al (2014) apontam, em recente trabalho realizado sobre a execução do Programa Minha Casa Minha Vida, em Belo Horizonte, fatores preocupantes como a produção de habitações em grandes conjuntos afastados da região central da cidade, com precárias redes de infraestrutura e transporte, além da reprodução, no programa, da noção do padrão mínimo adequado de moradia que a considera como produto a ser entregue a determinado beneficiário, que não pode participar autonomamente do seu processo de produção. Para os citados autores, a noção de habitação deve ser multi-escalar, implicando a consideração aos conceitos de habitat e habitar, sendo o primeiro referente à produção da unidade habitacional e o segundo ao exercício do direito à cidade.

O presente trabalho tem o objetivo de apresentar como as ocupações urbanas podem contribuir para a (re)construção dos espaços na cidade, que possibilitem a emergência de cidadanias e a redução de desigualdades, sem perder de vista o contexto em que se inserem.

\section{Aspectos metodológicos}

Como aporte metodológico da pesquisa, utiliza-se a cartografia social, em sua vertente jurídica, por se tratar de instrumento que permite a abordagem do fenômeno das ocupações urbanas em seus respectivos contextos sociais, políticos e jurídicos. Permite ainda a coparticipação de pesquisadores e moradores das localidades em estudo para a edificação de conhecimentos comuns. Esta maneira de construir o conhecimento possibilita compreender os processos que levam à formação e à consolidação das ocupações urbanas, bem como as peculiaridades e interconexões existentes nos processos de ocupação de terra em Belo Horizonte e Região Metropolitana.

Para a tradução dos resultados alcançados em "mapas sociais", foram realizados, além de estudos de material bibliográfico, dados sociais e processos judiciais, visitas e imersões nas comunidades, entrevistas, oficinas e discussão conjunta dos seus resultados por meio de encontros e da elaboração de cartilhas. Durante o período de fevereiro de 2013 a agosto de 2014, foram realizadas atividades de pesquisa empírica nas ocupações Dandara, Camilo Torres e Eliana Silva, localizadas em Belo Horizonte-MG, nas quais se observou que as formas de organização e resistência contribuem para (re)pensar e (re)construir os espaços da cidade.

Para a pesquisa na Comunidade Camilo Torres foram realizadas, além da análise da Ação de Reintegração de Posse e Ação Civil Pública', visitas à ocu- 
pação, entrevistas semiestruturadas e a oficina da cartografia social. Foram entrevistados doze moradores, selecionados segundo critérios de idade, sexo, tempo de residência e grau de mobilização comunitária, no intuito de abarcar a maior diversidade possível de residentes da ocupação. As entrevistas tiveram como temas estruturantes o histórico de envolvimento do morador com a ocupação, trabalho, direito à moradia, direito à cidade entre outros.

Na Comunidade Camilo Torres, a oficina de cartografia social foi realizada no Centro Comunitário da ocupação, no dia 23 de agosto de 2014. Ela contou com a presença de aproximadamente dez moradores adultos, algumas crianças e integrantes da pesquisa. Foram convidados moradores anteriormente entrevistados. Além disso, uma semana antes da mencionada atividade, foi feita ampla divulgação da oficina por meio da distribuição de convites pelos pesquisadores, em visita à ocupação.

A oficina transcorreu em uma tarde de sábado, de forma descontraída, com a realização de dinâmicas diversas, a partir das quais se pôde aferir os laços comunitários desenvolvidos, o histórico de mobilização da comunidade e o significado que ela tem para parte dos seus moradores. As dinâmicas adotadas consistiram nas seguintes atividades: representação dos moradores em um mapa da ocupação; discussão do conceito de direito à cidade; reconstituição da história da comunidade por meio da elaboração da linha do tempo; escrita e desenho dos sonhos dos moradores em papeis posteriormente colocados em uma "árvore dos sonhos".

Após a apresentação da pesquisa e dos pesquisadores, os participantes discorreram sobre parte da história de vida de Camilo Torres, que deu nome à ocupação. Discutiu-se com os moradores os significados do direito à cidade, da seguinte forma: enquanto os participantes diziam o que, para eles, representa direito à cidade, suas falas eram escritas em uma cartolina para posterior discussão e comparação dos conceitos por ele descritos com aqueles constantes no Estatuto da Cidade (Lei n ${ }^{\circ} 10257 / 2001$ ). Seguiu-se a essa discussão a confecção de linhas do tempo, feitas em cartolina, onde os moradores, divididos em dois grupos, recontaram os momentos mais significativos que viveram na comunidade, o que depois foi compartilhado entre os grupos. Durante um lanche coletivo, que permitiu maior aproximação entre pesquisadores e moradores, estes escreveram em papeis com formato de folhas de árvore, os seus sonhos para a comunidade, os quais depois foram pendurados em uma árvore montada pelos pesquisadores e deixada no Centro Comunitário da ocupação.

A seguir serão apresentados e analisados os dados coletados nas entrevistas realizadas e na oficina de cartografia social referentes à ocupação Camilo Torres, localizada em Belo Horizonte. 


\section{A formação da Comunidade Camilo Torres e sua inserção no contexto urbano de Belo Horizonte}

A Comunidade Camilo Torres é uma ocupação urbana localizada na Região do Barreiro, uma das áreas de maior concentração de serviços comerciais e industriais da capital mineira. Seu processo de formação iniciou-se em 16 de fevereiro de 2008, quando famílias sem-casa ocuparam um terreno ainda sem construção, que quedava ocioso no Bairro Vila Santa Rita localizado nesta Região, ao sul de Belo Horizonte. Trata-se de um bairro afastado do centro da capital, mas pertencente aos limites do município de Belo Horizonte. Apesar de ser área urbana periférica, o Barreiro conta com serviços básicos como transporte público, serviços de saúde, vias pavimentadas e uma área comercial. Segundo relatos do professor Fábio Alves dos Santos, advogado da Assistência Judiciária da PUC Minas que atuou na Ação de Reintegração de Posse² (MINAS GERAIS, 2014c), em abril de 2008, um contingente maior de famílias ocupou as áreas remanescentes do terreno, fato esse que foi o estopim para que a suposta proprietária da área, a empresa Victor Pneus, ingressasse em juízo com a referida ação (MIRANDA, 2014)

Em breve resgate do histórico cartorial do imóvel ocupado, obtido por meio da análise do processo acima mencionado, tem-se que ele pertencia à Companhia de Distritos Industriais (CDI-MG), atual Companhia de Desenvolvimento Econômico de Minas Gerais (CODEMIG), empresa pública integrante da Administração Indireta do Estado de Minas Gerais (MINAS GERAIS, 2014a). Em 1992, a CDI-MG alienou o imóvel à empresa Borvultex Comércio e Indústria Ltda., localizado na Avenida Perimetral, $\mathrm{n}^{\circ} 347$, Bairro Vila Santa Rita com suposta área de $12230 \mathrm{~m}^{2}$, local onde atualmente encontra-se a ocupação. Desta área, cerca de $9450 \mathrm{~m}^{2}$ são privados e, aproximadamente, $2770 \mathrm{~m}^{2}$ pertencem ao Município de Belo Horizonte. A empresa Borvutex assumiu, no contrato de alienação firmado com a CDI-MG, como encargo, o dever de construir no terreno um empreendimento industrial no prazo de 24 meses. Porém, a área restou em completo abandono até ser ocupada pelos moradores da comunidade. Ainda de acordo com o relato constante do processo judicial, em 2004, supostamente sem contar com a anuência da CODEMIG, a Borvutex Comércio e Indústria Ltda. prometeu vender à Victor Pneus o referido imóvel. Por força do Termo de Cessão de Direitos, a posse do imóvel teria sido repassada à citada empresa. Ressaltase que o valor da transação foi de apenas $\mathrm{R} \$ 15$ mil reais, enquanto somente o IPTU da área indicava o valor venal de R $\$ 250$ mil reais, segundo consta nos autos da ação possessória. $\mathrm{O}$ terreno continuou no mais completo aban-

Processo n. 0024.08.969.846-8/TJMG 
dono sem que a CODEMIG empreendesse qualquer medida para reverter ao patrimônio público o imóvel, considerando o não cumprimento do encargo. Atualmente o imóvel segue como objeto de disputa judicial, não apenas em sede da ação de reintegração de posse como, ainda, de ações civis públicas ajuizadas pela Defensoria Pública e pelo Ministério Público do Estado de Minas Gerais. Na esfera judicial, as discussões envolvem a disputa pela posse e propriedade do imóvel, questões ambientais e o direito à moradia dos ocupantes.

A ocupação foi articulada pelo Fórum de Moradia do Barreiro (FMB), por associações e núcleos de sem-casa que se organizaram para pressionar os governos a promoverem políticas públicas de acesso à moradia para população mais pobre da cidade e também pela organização social Brigadas Populares (AGÊNCIA DE NOTÍCIAS BRIGADISTAS, 2009).

Conforme demonstram os dados coletados na Comunidade Camilo Torres, as ocupações urbanas, na medida em que se apresentam como alternativas à produção segregacionista do espaço urbano, orientada por uma lógica individualista e mercadológica, têm o condão de fortalecer os laços de solidariedade entre os moradores que compartilham de uma mesma luta - a efetivação do direito à moradia. Harvey destaca, neste contexto, o papel dos movimentos sociais. Para o autor,

\footnotetext{
Há, porém, movimentos sociais urbanos tentando superar o isolamento e remodelar a cidade segundo uma imagem diferente daquela apresentada pelas incorporadoras imobiliárias, apoiadas pelos financistas, as grandes corporações e um aparato estatal local com mentalidade cada vez mais influenciada pelos negócios (HARVEY, 2013).
}

Os movimentos sociais de apoio, juntamente com os ocupantes, denominaram a comunidade de Camilo Torres, em homenagem ao padre-guerrilheiro colombiano, precursor da Teologia da Libertação, que integrou a guerrilha Exército de Libertação Nacional e morreu em combate contra o Exército Nacional da Colômbia no ano de 1966. Camilo Torres dedicou o sacerdócio e toda a sua vida aos pobres e à busca por justiça social.

Os momentos iniciais da ocupação, como relataram os moradores, foram marcados pelo conflito constante com a polícia. Em entrevista realizada em junho de 2014, o morador de perfil homem, mobilizado, vivendo na ocupação há mais de 6 (seis) anos, descreveu este contexto fático: 
Morador: Muita polícia, muita luta, muito sofrimento aqui. [...]

Entrevistador: Quando vocês chegaram, teve muita repressão da polícia?

Morador: Ave Maria!! Eu sou um dos que tomei spray de pimenta no olho umas duas veiz. O morador que passou aqui agora... foi preso, tiro de borracha. Ih... o outro, misericórdia. Os Guardas Municipal, a polícia... E quantas veiz eles vieram tirar nóis daqui... [...] $\mathrm{Na}$ minha época nego saiu endoidado aí por causa da polícia, saiu vendendo o barraco [após construir] por mil, 2 mil conto...

Além disto, foram relatadas as dificuldades inerentes ao estabelecimento de uma ocupação, tais como a precariedade de se viver em casas de lona, a ausência de infraestrutura básica nas habitações e no terreno, chuvas e outros infortúnios, inclusive problemas de saúde. Este fato foi evidenciado no seguinte trecho de entrevista, realizada em maio de 2014, com moradora do perfil mulher, mobilizada, vivendo na ocupação há mais de 6 (seis) anos:

Moradora: Mas no início a gente sofreu até de saúde aqui... Às
vezes a gente dava, como a gente não tava... acostumado com
tanta poeira, a gente tinha mal estar. O pessoal tinha vômito, ti-
nha... alergia... Ia no posto queimando de febre e eles não queria
atender. Cê ia passando mal, eles colocava seu nome, agendava
sua consulta pra quando marcar de chamar...

Assim, em contraposição a um modelo de produção da cidade pautado na verticalização das moradias, que solapa os laços de solidariedade entre vizinhos e estimula o individualismo compartimentado em apartamentos, o modelo de habitação promovido pelas ocupações permite a construção de espaços comuns de convivência, os quais são erigidos pelas assembleias de moradores - onde são discutidos os problemas internos das comunidades - e pelos eventos culturais promovidos nestes espaços, que permitem a interação dos moradores locais com indivíduos residentes em outras partes da cidade. A instituição destes espaços, por um lado, permite a consolidação do senso de coletividade entre os ocupantes e, por outro, possibilita a integração destes indivíduos com o restante da cidade. Essa solidariedade interna fica evidente na fala de um morador de perfil homem, morador da ocupação há mais de 4 anos, entrevistado entre maio e junho de 2014:

Entrevistador: O que representa pra você morar aqui hoje?

Morador: Ah, eu pra mim é orgulho, eu tenho orgulho de morar aqui, porque foi muita luta pra conseguir isso aqui. Muita gente 
não gosta, muita gente na rua você escuta muita gente falando 'cambada de favelado'. Mas melhorzim lugar que tem pra morar é aqui mesmo. É, que aqui um ajuda o outro, todo mundo é amigo de todo mundo.

\section{Linha do tempo: resistências de ontem e hoje}

Outros moradores também rememoraram o início da ocupação por meio da oficina de cartografia social, realizada no Centro Comunitário da ocupação em 23 de agosto de 2014, conforme citado anteriormente. Os participantes da oficina afirmaram que, no início da ocupação, enfrentaram a polícia que os ameaçava despejar e, para se consolidarem, organizaram diversas assembleias e manifestações até o centro da cidade, onde se localizam as sedes do poder municipal e estadual. Foram também à Brasília, evidenciando, assim, a busca pela possibilidade de negociação plausível com a garantia do direito à moradia frente à iminência de um despejo.

Destaca-se também o processo de construção conjunto das casas e do Centro Comunitário, local de uso coletivo na ocupação. Foram muitas as dificuldades vividas, em função da negativa inicial da demanda dos moradores pelo acesso a equipamentos públicos do bairro, tais como escola e posto de saúde, além do desabastecimento de serviços como água, energia elétrica e calçamento das ruas - problemas que ainda persistem nos dias atuais.

Percebe-se que, ao longo de seis anos de formação da ocupação Camilo Torres, diversos conflitos foram vividos pelos moradores, tais como os desgastes gerados pelas complicadas negociações com o poder público para o acesso a políticas públicas de moradia e outras prestações estatais; a precariedade dos serviços e infraestrutura básicos; os conflitos entre os moradores e os movimentos sociais, fatos que levaram, inclusive, a uma redução da mobilização comunitária - que se tornou mais notável nos anos recentes.

A linha do tempo construída a partir da Oficina de cartografia social realizada no Centro Comunitário da ocupação Camilo Torres, dia 23 de agosto de 2014 (Figura 1), conta a trajetória de vida dos moradores.

A análise final da linha do tempo permite aferir que os processos de formação e consolidação da ocupação envolveram a construção de lutas e empreendimentos comuns. Tal fato foi verificado por meio da construção de equipamentos coletivos, como a cozinha e o banheiro comunitários (2008) e o centro comunitário (2010), bem como através da realização de assembleias internas e de atos com outras ocupações (luta com a ocupação Dandara - 2009); caminhada das comunidades e ocupação da Praça 7 (Principal praça da área 
central da cidade de Belo Horizonte - MG) - 2010; ocupação do Ministério das Cidades - 2011; trancamento do Anel Rodoviário (Importante via de Belo Horizonte - MG) com a ocupação Irmã Dorothy - 2011. Observou-se, assim, não só a ampliação da base de apoio da comunidade como o desenvolvimento de uma rede de apoio entre as ocupações urbanas, notadamente a partir dos contatos realizados em atos conjuntos.

Figura 1 - Linha do tempo

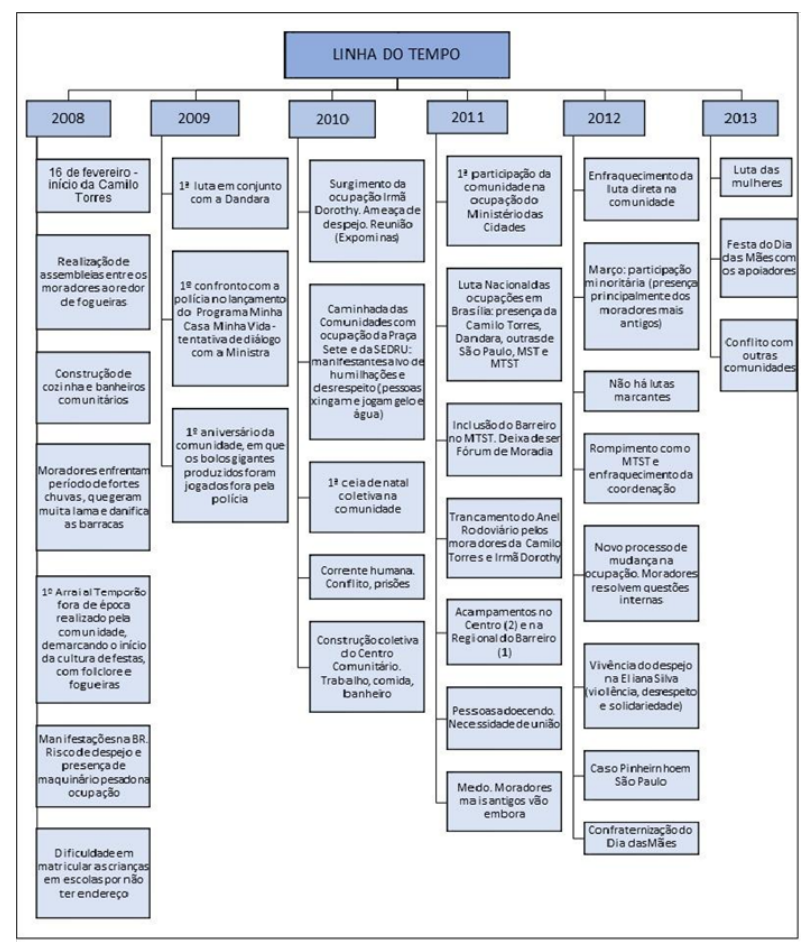

Fonte: Dados obtidos pelos autores em pesquisa direta - Cartografia sociojurídica da Comunidade Camilo Torres

Destaca-se também a realização de festas, que ressaltam o sentido de pertencimento e reforçam o sentido da luta pelos direitos à moradia adequada e à cidade. Durante a realização da oficina, os moradores relembraram com afeto e intensidade as festas ocorridas especialmente nos primeiros anos de ocupação: o Arraial fora de época em 2008; o primeiro aniversário da comunidade em 2009; a ceia de natal coletiva em 2010 e as festas do dia das mães de 2012 e 2013. Relataram também as dificuldades passadas conjuntamente, tal como o enfrentamento da polícia e o adoecimento de inte- 
grantes da comunidade, que demandaram a união de todos. A partir de 2011, as dificuldades dizem respeito a certa desmobilização comunitária. Foram retratadas na linha do tempo a saída de moradores em função do medo que sentiam; o enfraquecimento da luta direta na comunidade; o rompimento com o Movimento dos Trabalhadores Sem Terra e o enfraquecimento da coordenação interna, além da vivência do despejo da ocupação Eliana Silva, em Belo Horizonte, e a de Pinheirinhos, em São Paulo, caso este que ganhou grande repercussão midiática.

Os ganhos e as dificuldades vividos em conjunto ressaltam o desenvolvimento de um sentido político dado à existência de muitas das famílias residentes na ocupação Camilo Torres, que, ao terem de lutar por moradia digna, terminaram por se engajar em um projeto comum que, em suma, diz respeito à efetivação do direito à cidade. Nas linhas que se seguem, serão descritas as amplas e ricas concepções que os moradores têm deste direito, fruto do percurso deles na construção de um novo espaço na cidade.

\section{O direito à cidade e a construção de espaços na cidade}

Os artigos 182 e 183 da Constituição Federal (BRASIL, 1988), que tratam da política urbana, discorrem que esta objetiva o ordenamento do pleno desenvolvimento das funções sociais da cidade e a garantia do bem-estar de seus habitantes, e definem os meios legítimos ao exercício do domínio sobre a terra. Por meio do Estatuto da Cidade (BRASIL, 2001), que regulamenta esses dois artigos, foram estabelecidas as normas e diretrizes para que o direito à cidade seja garantido como direito fundamental, por meio do exercício da função social da propriedade e da cidade.

$\mathrm{Na}$ medida em que decorria a oficina de cartografia social, momento que se passou a discutir o direito à cidade, os dados coletados demonstraram que os moradores participantes possuem uma compreensão ampla desse direito, o que se confirma também pelo envolvimento dos mesmos nos assuntos comunitários. De acordo com os moradores presentes, o direito à cidade representa, em especial, o direito de poder participar, ter voz ativa nas questões que implicam sobremaneira nas condições de vida, além do direito de ser servido, no local de residência, de infraestrutura adequada e de serviços que permitem o bem-estar individual e comunitário. Significa também ter condições garantidas de acessibilidade ao lazer e a um endereço e não sofrer ameaça de remoções, ou seja, viver com a segurança da posse. A Figura 2 consolida os dados coletados e demonstram a concepção da comunidade sobre o tema. 
Figura 2: Reprodução da dinâmica sobre direito à cidade

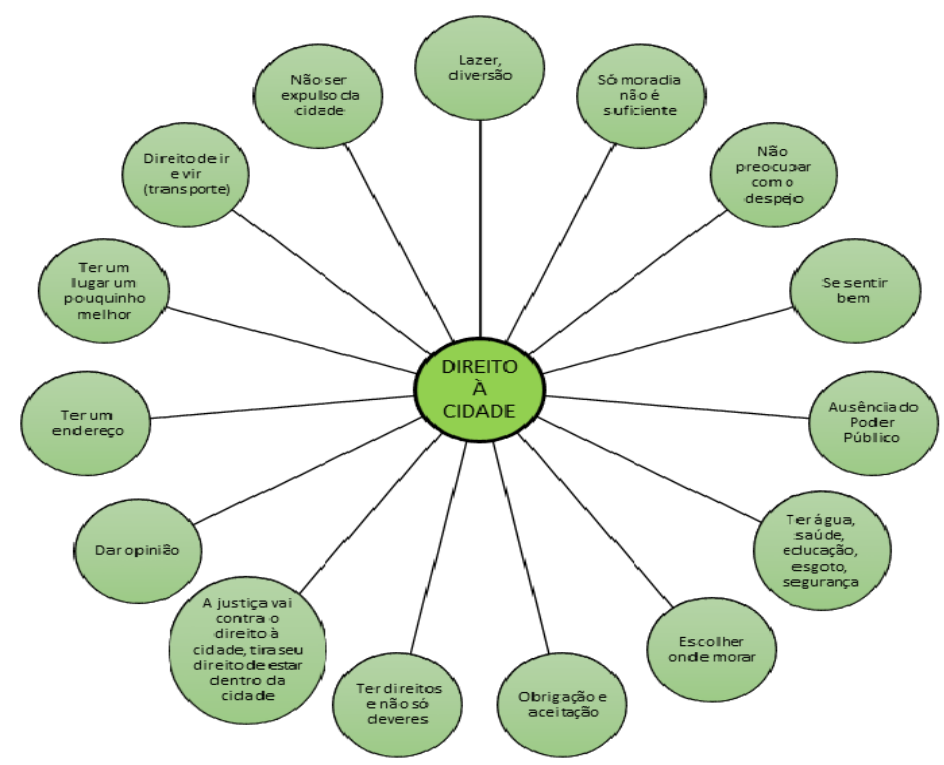

Fonte: Dados obtidos na Oficina de cartografia social realizada no Centro Comunitário da ocupação Camilo Torres, dia 23 de agosto de 2014. (Pesquisa Direta. Cartografia sociojurídica da Comunidade Camilo Torres)

A pesquisa empírica realizada na Comunidade Camilo Torres também demonstrou que o processo de formação e consolidação das ocupações urbanas em Belo Horizonte está intimamente ligado à busca pela recriação do espaço urbano a partir de novas dinâmicas sociais e políticas que se integram ao uso do espaço cotidiano da cidade, tendo como ponto central a efetivação do direito à moradia.

Nesse sentido, o direito à cidade foi compreendido pelos moradores como direito humano eminentemente coletivo e que coloca em xeque toda a lógica segregacionista de uso, ocupação e produção do espaço urbano, vislumbrandose a primazia das relações humanas e humanizadoras frente a uma lógica mercadológica determinante nas relações socioespaciais. As afirmações dos moradores sobre "escolher onde morar", "ter um lugar um pouquinho melhor", "não ser expulso da cidade", constantes da Figura 2, demonstram esta assertiva.

Portanto, ao se empoderarem - numa relação interativa com outros sujeitos de direitos que compartilham das mesmas dificuldades - os moradores das ocupações resgataram a dimensão contestatória e crítica, evidenciando a capacidade de oposição no campo da política, visando à (re)construção de uma cidade efetivamente humana. Nos relatos sobre "direito à cidade" também ficou evidenciado a preocupação e o embate com o Poder Judiciário - seja porque afirmou-se 
que "A justiça vai contra o direito à cidade, tira o seu direito de estar dentro da cidade" - e com o Poder Executivo - quando afirmam que há "ausência do Poder Público" e falta de acesso a serviços públicos considerados essenciais.

Neste mesmo sentido são os dizeres do geógrafo David Harvey acerca do direito à cidade:

\begin{abstract}
Saber que tipo de cidade queremos é uma questão que não pode ser dissociada de saber que tipo de vínculos sociais, relacionamentos com a natureza, estilos de vida, tecnologias e valores estéticos nós desejamos. O direito à cidade é muito mais que a liberdade individual de ter acesso aos recursos urbanos: é um direito de mudar a nós mesmos, mudando a cidade. Além disso, é um direito coletivo, e não individual, já que essa transformação depende do exercício de um poder coletivo para remodelar os processos de urbanização. A liberdade de fazer e refazer as nossas cidades, e a nós mesmos, é, a meu ver, um dos nossos direitos humanos mais preciosos e ao mesmo tempo mais negligenciados (HARVEY, 2013).
\end{abstract}

Os direitos à moradia e à cidade também foram objeto de estudos e reflexões do geógrafo Milton Santos. O referido autor problematiza a confusão conceitual que há na literatura jurídica entre direito de morar e direito de ser proprietário: "Por enquanto, o que mais se conseguiu foi consagrar de uma visão imobiliária da cidade, que impede de enxergá-la como uma totalidade." (SANTOS, 2007, p. 61)

As próprias percepções dos moradores corroboram esta ideia de que há uma hegemonia e consagração da visão imobiliária da cidade. A noção de cidadania atrelada a viver numa área legalizada e, assim, pagar regularmente os impostos, foi afirmada constantemente nas entrevistas realizadas na Comunidade Camilo Torres. É o que se vê em entrevista realizada no período entre maio e junho de 2014 com morador de perfil homem, jovem ou idoso, morador da ocupação há menos de 3 anos, não mobilizado:

Entrevistador: Qual o seu sonho aqui pra comunidade, como você enxerga?

Morador: No meu enxergá aqui é o seguinte, a comunidade aqui ser um bairro legalizado, cada um com a sua moradia e luz e água instalado aqui pra nós. O sonho nosso é olhá pra isso com esgoto instalado e poste e energia por nossa conta, pra cada um ter a sua moradia digna.

Talvez a condição de viver em área legalizada e pagar os mesmos impostos que os demais moradores da cidade pagam os façam reconhecer-se como 
parte dessa cidade. Além disso, o impedimento de enxergar a cidade como um todo, que é um dos efeitos diretos dessa visão imobiliária de cidade, também foi notado. Em determinadas entrevistas, quando o entrevistador questionou o papel que a comunidade desempenha para a cidade como um todo, os moradores titubeiam. É provável que as relações e o diálogo com as outras partes da cidade estejam apartados do cotidiano dessas pessoas. Na entrevista, realizada em junho de 2014, com uma moradora há mais de seis anos, de perfil jovem, não mobilizado, isso pode ser percebido nas seguintes afirmações:

Entrevistadora: Você acha que a Camilo Torres cumpre um papel dentro da cidade como um todo assim? Tem uma importância na cidade?

Moradora: Ah eu acho que tem né, eu acho que tem.

Entrevistadora: Qual que você acha que é esse papel?

Moradora: Ah...rs... é muita coisa...falar...

Entrevistadora: Mas o que que você acha, o que que você pensa assim, da importância da luta dos movimentos...

Moradora: Ah... não sei... hehe..

Entrevistador: Você acha que a Comunidade traz alguma coisa pra cidade? Tem alguma importância para Belo Horizonte. Você acha que é exemplo?

Moradora: Nessa parte nem sei responder direito, mas eu espero que seja uma coisa pro futuro né?

Ademais, já se tornou senso comum entre os moradores a morosidade e ineficácia das políticas públicas de habitação. Isso é constatado no discurso das entrevistas, a exemplo desta realizada em junho de 2104, cujo entrevistado é homem, morador da ocupação há 4 anos, na qual afirmou:

Entrevistador- Você quer falar alguma coisa, acrescentar?

Entrevistado- Não, só queria falar assim que tem que fazer ocupação mesmo porque se esperar o "Minha Casa, Minha vida" você vai morrer esperando.

Uma ocupação urbana - por meio de suas dinâmicas internas e das fronteiras e diálogos que estabelece com a cidade formal - contribui para repen- 
sar a noção de direito à cidade, através dos seus processos cotidianos de (re) construção. Contribui para a revisão das políticas públicas de habitação hoje empregadas em larga escala em territórios municipais que, além de não terem reduzido amplamente o déficit habitacional, desvinculam a habitação de temas centrais à efetivação do direito à cidade. Também colaboram para uma avaliação crítica dos modos de governança pautados em uma gestão funcional e/ ou mercantilizada da cidade. Diante desse contexto, torna-se contundente a expressão dos movimentos sociais de luta por moradia em Belo Horizonte, ao afirmarem que: "quando morar é um privilégio, ocupar é um direito".

Um direito, ressalta-se, cuja necessidade de realização se expressa através de sonhos. Na última dinâmica realizada na mencionada oficina de cartografia social, a "árvore dos sonhos", seus moradores exprimiram que almejam para o lugar onde vivem edificações materiais como creches e parques, abastecimento de luz elétrica, água, esgoto e asfaltamento, mas também questões imateriais como a paz de se ter um lugar onde morar sem ameaças, como pode ser visto, em síntese, na Figura 3.

Figura 3: Reprodução da dinâmica "árvore dos sonhos"

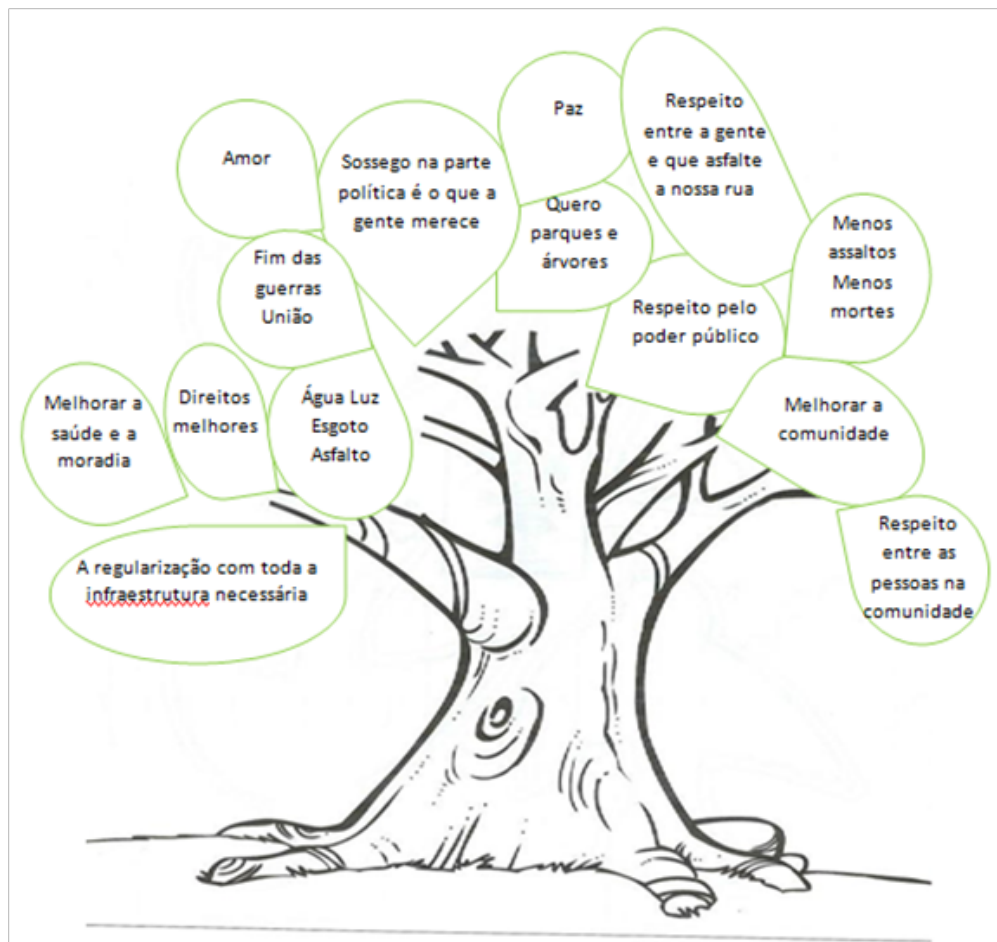

Fonte: Dados obtidos na Oficina de cartografia social realizada no Centro Comunitário da ocupação Camilo Torres, dia 23 de agosto de 2014. (Pesquisa Direta. Cartografia sociojurídica da Comunidade Camilo Torres) 


\section{Considerações finais}

As ocupações urbanas, para além da efetivação do direito à moradia à revelia do Estado, promovem alterações espaciais na cidade. Tais modificações se dão na ordem simbólica e estrutural. No plano simbólico, se constituem como verdadeiros territórios de luta por reconhecimento com potencial de rompimento para com a lógica de ocupação majoritária. Ao proporem, por meio da ocupação, uma nova relação entre o indivíduo e a cidade que não se baseia nas interações clássicas, questionam também o papel do direito positivo.

No plano estrutural, ocorre ainda uma alteração paisagística, na qual a ocupação passa a marcar o território e demandar do Estado o acesso e pertencimento à cidade formal. A luta por direitos passa a se dar também a partir de outra lógica. $\mathrm{O}$ que está em jogo não é somente o direito à moradia. Depois da conquista da casa, o Estado passa a ser demandado na área da saúde, educação, transporte etc.

Esses territórios, portanto, têm um potencial questionador da própria ocupação urbana do espaço urbano de Belo Horizonte e Região Metropolitana. Sua constituição, produto da organização e mobilização da cidadania, contribui para a reconstrução dos espaços participativos na cidade. Verifica-se, portanto, a identificação de uma cidadania insurgente.

$\mathrm{O}$ mapeamento proposto pela pesquisa conseguiu ter acesso à parte da dinâmica de apropriação da cidade pelas ocupações urbanas. Conseguiu também levantar a nova dinâmica discursiva onde o Direito à Cidade está inserido como direito fundamental. $\mathrm{O}$ feixe de direitos que o Direito à Cidade carrega consigo faz com que haja movimentação social politizadora em torno de sua concretização. Observou-se, ainda, que as noções de pertencimento e solidariedade se intensificam numa dimensão emancipatória.

Esse potencial emancipatório insurgente, a partir das ocupações urbanas, está em construção. O que se verifica é uma nova forma de apropriação da cidade e dos espaços de participação popular. Exemplo desta nova apropriação é a autoconstrução das moradias - que confronta a atual formulação e gestão de políticas públicas de moradia pela ampliação dos espaços de deliberação constituídos pelos moradores, que, organizando-se em assembleias comunitárias, decidem politicamente sobre vários aspectos de suas comunidades. Ao reivindicarem seus direitos, modificam as políticas públicas e a atuação dos atores sociais envolvidos na questão, inclusive os institucionais. Na ótica dos ocupantes, os direitos fundamentais à cidade e à moradia deixam de ser conferidos por um Estado socialmente comprometido e se revelam como verdadeiras conquistas. A organização para a ocupação, os 
enfrentamentos com os agentes da repressão estatal, o combate ao estigma e o preconceito são exercícios diários da luta por reconhecimento e efetividade de direitos sociais.

"Não ser expulso da cidade": assim um morador definiu o que significa o direito à cidade. Para além de ter os próprios direitos assegurados por meio da luta, uma ocupação versa principalmente sobre resistência. No caso da Camilo Torres, tal resistência apresenta-se quando os moradores recordam seus momentos de construção e consolidação, as assembleias, marchas e manifestações realizadas, enfim, a própria persistência em morar diante da iminente ameaça de despejo.

Considerando o caso da Comunidade Camilo Torres, tem-se que a cidade pode aprender com as ocupações como promover a (re)construção espacial do espaço urbano, o que pode ser depreendido do apoio que moradores de outras partes da cidade oferecem às comunidades - através da organização e participação nos eventos culturais promovidos nas ocupações -, e também da solidariedade e união existente entre a ocupação Camilo Torres e outros assentamentos existentes na cidade, que, juntos, organizam em marchas e manifestações a luta pela efetivação do direito à moradia e à cidade. Mesmo que o reconhecimento da ocupação Camilo Torres como movimento legítimo pela efetivação do direito à moradia encontre obstáculos ao seu exercício também encontra apoio institucional e social. Isso destaca o potencial transformador das ocupações e o processo democrático e conflitivo que conhece avanços, retrocessos e muitos momentos de tensão, mas que possui como noção intrínseca o aprendizado emancipador da ação e vida em comum.

\section{Referências}

AGÊNCIA DE NOTÍCIAS BRIGADISTAS. Fórum de Moradia do Barreiro e Brigadas Populares: juntos na luta por uma nova cidade.[S.1.]17 de setembro de 2009. Disponível em: http:// agenciabrigadista.blogspot.com.br/2009/09/forum-de-moradia-do-barreiro-e-brigadas.html Acesso em 02 nov. 14.

ANDRADE, Luciana Teixeira de. Segregação socioespacial e construção de identidades urbanas na RMBH. In: MENDONÇA, Jupira Gomes de; GODINHO, Maria Helena de Lacerda (Orgs.) População, espaço e gestão na metrópole: novas configurações, velhas desigualdades. Belo Horizonte: PUC Minas, 2003. 336p.

BORDIN, Luigi. Camilo Torres - testemunho e profecia. Centro de Pesquisas Estratégicas Paulino Soares de Sousa, Universidade Federal de Juiz de Fora, s/d. Disponível em: http://www. ecsbdefesa.com.br/fts/CamiloTorres.pdf. Acesso em 02 nov. 14.

BRASIL. Constituição (1988). Constituição da República Federativa do Brasil. Brasília, DF: Senado Federal: Centro Gráfico, 1988. 292 p. 
BRASIL. (Presidência da República). Estatuto da Cidade: Lei 10.257/2001. Regulamenta os arts. 182 e 183 da Constituição Federal, estabelece diretrizes gerais da política urbana e dá outras providências.Brasília, 10 de julho de 2001. Disponível em: http://www.planalto.gov.br/ ccivil_03/leis/leis_2001/110257.htm. Acesso em: 06 nov. 2014.

DIAS, Maria Tereza Fonseca et al. Ocupações urbanas e direito à cidade: excertos da cartografia sociojurídica da comunidade Dandara, em Belo Horizonte. In: DIAS, Maria Tereza Fonseca; BARBOSA, Maria Eliza Braz; COSTA, Mila Batista Corrêa; CORDEIRO, Caio. Estado e propriedade: estudos em homenagem à Professora Maria Coeli Simões Pires. Belo Horizonte: Fórum, 2015, p. 361-384.

DIAS, Maria Tereza Fonseca; COSTA, Stéfane Rabelo Pereira da. Popular participation in the Housing City Council of Belo Horizonte, Brazil: institutionalization, democratization and representation. Business and Management Review, SpecialIssue, v. 4, n. 7, February, 2015. Disponível em: http://www.bmreview.org/103.asp. Acesso em: 28 fev. 2015

FERRARI, Júnia; SILVA, Ana Flávia; ESCADA, Gabriel; OLIVEIRA, Laís; CRUZ, Mariana; ALENCAR, Vitor. Habitação na RMBH: Programa social ou de mercado? Disponível em: http://web.cedeplar.ufmg.br/cedeplar/seminarios/ecn/ecn-mineira/2014/site/arquivos/habitacao-na-rmbh--programa-social-ou-de-mercado.pdf. Acesso em: 02 nov. 2014.

FÓRUM MINEIRO DE DIREITOS HUMANOS. Comunidades Ameaçadas De Desalojamento Na Regional Barreiro - BH. Fórum Mineiro de Direitos Humanos, 21 de março de 2011. Disponível em: http://fmdireitoshumanos.blogspot.com.br/2011_03_01_archive.html. Acesso em: 02 nov. 2014.

HARVEY, David. O direito à cidade. Piauí. Edição 82, Julho de 2013, Estadão. Disponível em: http://revistapiaui.estadao.com.br/edicao-82/tribuna-livre-da-luta-de-classes/o-direito-a-cidade, acesso em: 03.11.2014.

INSTITUTO DE PESQUISA APLICADA - IPEA. Estimativas do Déficit Habitacional brasileiro (PNAD 2007-2012). Nota Técnica N 5, Brasília, D.F., nov. 2013.

MENDONÇA, Jupira Gomes de; COSTA, Heloísa Soares de Moura. Entre a homogeneização e a diversidade:segregação socioespacial na metrópole belo-horizontina e as especificidades do eixo sul. Espaço \& Debates, São Paulo, v. 8, n. 45, p. 75-86, 2004.

MINAS GERAIS. Companhia de Desenvolvimento Econômico de Minas Gerais. Perfil e histórico. Disponível em: <http://www.codemig.com.br/> Acesso em: 10 out. 2014a.

MINAS GERAIS. Tribunal de Justiça. Ação de Reintegração de posse nº 0024.08.969.846-8. Disponível em: http://www4.tjmg.jus.br/juridico/sf/proc_resultado.jsp?tipoPesquisa=1\&comr-

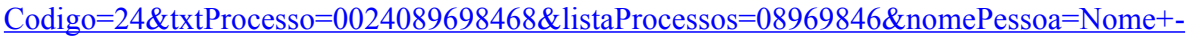
da + Pessoa\&tipoPessoa $=X \&$ naturezaProcesso $=0 \&$ situacaoParte $=X \& \operatorname{codigoOAB}=\&$ tipoO$\underline{\mathrm{AB}=\mathrm{N} \& u f O A B=M G \& \text { tipoConsulta=1\&n}}$. Acesso em: 09 nov. $2014 \mathrm{~b}$

MINAS GERAIS. Tribunal de Justiça. Ação de Reintegração de posse $n^{\circ}$ 0024.08.235950-6. Disponível em: http://www4.tjmg.jus.br/juridico/sf/proc_resultado.jsp?tipoPesquisa=1\&comrCodigo $=24 \&$ txtProcesso $=0024082359506 \&$ listaProcessos $=08235950 \&$ nomePessoa $=$ Nome +$\underline{\mathrm{da}}+$ Pessoa\&tipoPessoa $=\mathrm{X} \&$ naturezaProcesso $=0 \&$ situacaoParte $=\mathrm{X} \& \operatorname{codigoO} \mathrm{OB}=\&$ tipoO-

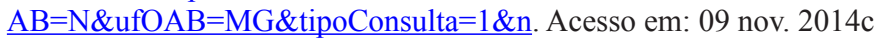


MIRANDA, Matheus Moura. Mapeamento de ocupações urbanas em Belo Horizonte: o direito à moradia em juízo. 2014, 67 f. (Monografia de Conclusão de Curso de Graduação em Direito). Faculdade de Direito da UFMG, Belo Horizonte, 2014.

SANTOS, Milton. O Espaço do Cidadão. São Paulo: EdUSP, 2007. 167 p.

VAINER, Carlos B. Pátria, empresa e mercadoria: notas sobre a estratégia discursiva do planejamento estratégico urbano. In: ARANTES, Otília; VAINER, Carlos e MARICATO, Ermínia. A cidade do pensamento único - Desmanchando consensos. Editora Vozes, Petrópolis, 2011. p. $75-104$.

Submissão em: 09/02/2015

Aceite em: 13/04/2015

Maria Tereza Fonseca Dias é mestre e doutora em Direito Administrativo pela UFMG. Professora Adjunta do Departamento de Direito Público da UFMG e dos cursos de graduação e pós-graduação stricto sensu da Universidade FUMEC. Pesquisadora de Produtividade do CNPq (PQ2), Coordenadora Adjunta do Programa Cidade e Alteridade (UFMG, CNPq, MEC/Proext / CIMOS - MPMG). Endereço para correspondência: Faculdade de Direito da UFMG - Av. João Pinheiro, 100, Bairro: Centro - CEP: 30130-180 - Belo Horizonte - MG. E-mail: mariaterezafdias@yahoo.com.br

Juliano dos Santos Calixto é bacharel, mestre e doutorando em Direito - UFMG. Foi professor substituto da Universidade Federal de Lavras. Orientador de campo do grupo de Pesquisa Mapeamento das Ocupações Urbanas de Belo Horizonte e Região Metropolitana, do Programa Cidade e Alteridade. E-mail:julianodsc@gmail.com

Larissa Pirchiner de Oliveira Vieira é bacharela em Direito pela FDMC e Mestre pelo NPGAU-UFMG. Foi orientadora de campo do Grupo de Pesquisa Mapeamento das Ocupações Urbanas de Belo Horizonte e Região Metropolitana do Programa Cidade e Alteridade.. E-mail:1arissapov@gmail.com

Carolina Spyer Vieira Assad é bacharela em Direito - PUCMINAS, Mestranda em Direito/UFMG e orientadora de campo do grupo de Pesquisa Mapeamento das Ocupações Urbanas de Belo Horizonte e Região Metropolitana. E-mail: caspyer@hotmail.com

Ananda Martins Carvalho é graduada em Psicologia - UFMG, mestranda no Núcleo de Pós Graduação em Arquitetura e Urbanismo - UFMG e orientadora de campo da Pesquisa Mapeamento das Ocupações Urbanas de Belo Horizonte e Região Metropolitana. E-mail: anandamartins91@gmail.com 
Amanda Reis da Silva é graduanda em Direito-UFMG e pesquisadora do grupo de Pesquisa Mapeamento das Ocupações Urbanas de Belo Horizonte e Região Metropolitana. E-mail: $\underline{\text { amandareisdasilva@gmail.com }}$

Fúlvio Alvarenga Sampaio é graduando em Direito - UFMG e foi pesquisador do grupo de Pesquisa Mapeamento das Ocupações Urbanas de Belo Horizonte e Região Metropolitana. E-mail: fulvioalvsampaio@gmail.com

Ingrid de Paula é graduanda em Ciências do Estado - UFMG e pesquisadora do grupo de Pesquisa Mapeamento das Ocupações Urbanas de Belo Horizonte e Região Metropolitana. E-mail: ingrid-bh8@hotmail.com

Letícia Araújo Leite é bacharela em Direito - PUCMINAS e foi pesquisadora do grupo de Pesquisa Mapeamento das Ocupações Urbanas de Belo Horizonte e Região Metropolitana. E-mail: leticia.aleite13@gmail.com

Lucas Nasser Marques de Souza é graduando em Ciências Sociais - UFMG e Direito pela Faculdade de Direito Milton Campos e pesquisador do grupo de Pesquisa Mapeamento das Ocupações Urbanas de Belo Horizonte e Região Metropolitana. E-mail: lucasnassermarques@gmail.com

Marcos Bernardes Rosa é graduando em Direito - UFMG e foi pesquisador do grupo de Pesquisa Mapeamento das Ocupações Urbanas de Belo Horizonte e Região Metropolitana. E-mail: markimrosa@gmail.com 